dernização desse estratégico setor, ou seja, o legislador brasileiro acompanhou, ainda que com atraso, a tendência mundial que pauta pela privatização de diversos serviços públicos, como forma e modo de se buscar maior eficiência e menores custos, ou como dizem "fazer mais por menos".

\section{As relações de trabalho}

Outro avanço contemplado pela Lei $\mathrm{n}^{\circ}$ 8.630 , é a nova disciplina às relações capital/ trabalho. Embora ela não tenha regulado direitos e obrigações entre trabalhadores e seus tomadores de serviços, a lei eliminou o abusivo e danoso monopólio detido pelos vários sindicatos da orla marítima, impostos e aceitos por conveniência e omissão tanto das autoridades como dos próprios embarcadores. A lei retirou dos sindicatos a condição de fornecerem o trabalho da mãode-obra avulsa, fator de elevados custos na movimentação de cargas e de abusos generalizados, a impedir o avanço tecnológico.

A partir da nova lei, a mão-de-obra avulsa não será mais imposta pelos sindicatos. $\mathrm{O}$ órgão gestor de mão-de-obra passou a ser responsável pelo registro, treinamento e remuneração do trabalhador portuário, nos moldes do que existe nos principais portos internacionais. Evidentemente que o citado órgão terá que cumprir as condições constantes dos acordos negociados entre empresários e trabalhadores. E nisso reside importante mudança introduzida pela lei, substituindo velho procedimentos, remetendo trabalhadores e empresários à negociação coletiva, principalmente a nível regional. Será, portanto, na mesa de negociação, que empresários trabalhadores estabelecerão as con- dições de trabalho, a remuneração, a definição das funções, a composição dos ternos na busca, assim, da permanente melhoria dos serviços portuários e da produtividade. Com isso, deixando de ser fornecedores de mãode-obra - atividade incompatível para a entidade classista!

Importante ressaltar que o órgão gestor de mão-de-obra (OGMO) terá um Conselho Supervisor composto por trabalhadores e empresários, bem como uma Comissão Paritária com a finalidade de solucionar litígios nas relações capital-trabalho.

Atento às repercussões sociais decorrentes do novo regime de exploração portuária notadamente pela introdução de modernos sistemas de carga e descarga, o legislador estabeleceu, para atenuar o período de transição, o sistema de compensação pecuniária para os trabalhadores não aproveitados, nas condições recomendadas pela Organização Internacional do Trabalho - (OIT)

Digno de registro, portanto, é o fato da nova lei ter revogado todo aquele emaranhado conjunto de atos normativos, passando a vigir novo ordenamento jurídico para o sistema portuário, que, se aplicado e cumpri do devidamente, dará não as melhores, mas aquelas condições mínimas para que o país possa se desenvolver social e economicamente num ritmo mais adequado às suas gigantescas necessidades sociais e econômicas.

\section{Bibliografia}

Catharino, José Martins. O Novo Sistema Portuário Brasileiro. Ed. Destaque, 1994

Oliveira, Carlos Tavares de. Modernização dos Portos. Ed. Aduaneiras, 1994.

Silva, Francisco Carlos de Morais. Direito Portuário. Ed. Del Rey, 1994.

\title{
A nulidade da lei inconstitucional e seus efeitos:
}

Consideração sobre a decisão do STF proferida no RE $n^{\circ} 122.202$

\section{Gilmar Ferreira Mendes}

Procurador da República, Professor da Universidade de Brasília, Mestre em Direito pela Universidade de Brasília, Doutor em Direito pela

Universidade de Münster - RFA.

SUMÁRIO

1. Introdução; 2. A nulidade da lei inconstitucional; 3. A nulidade ipso jure e ex tunc; 4. A nulidade da lei e os atos singulares praticados com base na lei inconstitucional; 5. Conclusão; Bibliografia.

\section{Introdução}

Em acórdão recém-publicado, o Supremo Tribunal Federal vem de afirmar que a retribuição de servidor público declarada inconstitucional não é de ser devolvida no período da validade inquestionada da lei, tal como se lê na ementa do acórdão:

"Recurso Extraordinário. Efeitos da Declaração de Inconstitucionalidade em tese pelo Supremo Tribunal Federal. Alegaşão de Direito Adquirido. Acórdão que prestigiou lei estadual à revelia da declaração de inconstitucionalidade desta última pelo Supremo. Subsistência do pagamento de gratificação mesmo após a decisão erga omnes da Corte. Jurisprudência do STF no sentido de que a retribuição declarada inconstitucional não é de ser devolvida no período de validade inquestionada da lei de origem - mas tampouco paga após a declaração de inconstitucionalidade. Recurso extraordinário provido em parte"1.

Cuidava-se de recurso extraordinário interposto pelo Estado de Minas Gerais contra decisão do Tribunal de Justiça daquele Estado que deferiu mandado de segurança para determinar a continuidade de pagamento de vantagens consagradas em lei já declarada inconstitucional pelo Supremo Tribunal.
Anteriormente já havia o Supremo Tribunal concluído que "a irredutibilidade dos vencimentos dos magistrados garante, sobretudo, o direito que já nasceu e que não pode ser suprimido sem que sejam diminuidas as prerrogativas que suportam o seu cargo". Por essa razão, afirmouse, tal garantia haveria de superar o próprio efeito ex tunc da declaração de inconstitucionalidade da norma ${ }^{2}$.

A decisão mais recente, também relativa à remuneração de magistrados, retrata entendimento no sentido de que "retribuição declarada inconstitucional não é de ser devolvida no período de validade inquestionada da lei de origem - mas tampouco paga após a declaração de inconstitucionalidade ${ }^{\Perp 3}$.

A orientação esposada pelo Supremo Tribunal nos casos referidos merece uma análise mais atenta.

Contemple-se, inicialmente, a chamada nulidade da lei inconstitucional.

\section{A nulidade da lei inconstitucional}

O dogma da nulidade da lei inconstitucional pertence à tradição do direito brasileiro. A teoria da nulidade tem sido sustentada por praticamente todos os nossos importantes 
constitucionalistas ${ }^{4}$. Fundada na antiga doutrina americana, segundo a qual "the inconstitucional statute is not law at all" ficativa parcela da doutrina brasileira posicionou-se em favor da equiparação entre inconstitucionalidade e nulidade. Afirmava-se, em favor dessa tese, que o reconhecimento de qualquer efeito a uma lei inconstitucional importaria na suspensão provisória ou parcial da Constituição 6 .

A recepção da doutrina americana não contribuiu significativamente para o desenvolvimento de uma teoria da nulidade da lei inconstitucional no Direito brasileiro. Também a fundamentação dogmática da chamada nulidade de pleno direito ou ipso jure jamais se afigurou precisa entre nós. Assim, constatou Lúcio Bittencourt que os constitucionalistas brasileiros não lograram fundamentar nem a eficácia erga omnes, nem a chamada retroatividade ex tunc da declaração de inconstitucionalidade proferida pelo Supremo Tribunal Federal 7 .

É o que se lê na seguinte passagem de seu magno trabalho:

"(...) as dificuldades e problemas surgem, precisamente, no que tange à eficácia indireta ou colateral da sentença declaratória da inconstitucionalidade, pois, embora procurem os autores estendê-la a situações jurídicas idênticas, considerando indiretamente anulada a lei, por que a "sua aplicação não obteria nunca mais o concurso da justiça", não têm, todavia, consegui do apresentar fundamento técnico, razoavelment aceitável, para justificar essa extensão.

Não o apontam os tratadistas americanos infensos à sistematização, que caracteriza os pa ses onde se adota a codificação do direito positivo - limitando-se a enunciar o princípio, em termo categóricos: a lei declarada inconstitucional deve ser considerada, para todos os efeitos, como se ja mais em qualquer tempo, houvesse possuido eficácia jurídica - is to be regarded as having never at any time, been possessed of any legal force.

Os nossos tratadistas também não indicam a razão jurídica determinante desse efeito amplo.
Repetem a doutrina dos escritores americanos as afirmaçôes dos tribunais, sem buscar-lhes o motivo, a causa ou ofundamento. Nem o grande Rui, com o seu gênio estelar, nem os que subseqüentemente, na sua trilha luminosa, versaram o assunto com a proficiência de um Castro Nunes" 8

Sem dispor de um mecanismo que emprestasse força de lei ou que, pelo menos, conferisse caráter vinculante às decisões do Supremo Tribunal Federal para os demais tribunais tal como o stare decisis americano, contentava-se a doutrina brasileira em ressaltar a evidência da nulidade da lei inconstitucional ${ }^{9}$ e a obrigação dos órgãos estatais de se absterem de aplicar disposição que teve a sua inconstitucionalidade declarada pelo Supremo Tribunal Federal ${ }^{10}$. O constituinte de 1934 introduziu a chamada suspensão de execução da le através do Senado Federal (art. 91, inciso IV) com o propósito inequívoco de emprestar força normativa às declarações de inconstitucionalidade proferidas inciden-talmente pelo Supremo Tribunal Federal ${ }^{11}$. Esse instituto fo incorporado à Constituição de 1946 (art. 64) à Constituição de 1967/69 (art. 42, VII), e mantido na Constituição de 1988 (art. 52, X) Esse ato do Senado Federal conferia eficácia erga omnes à declaração de inconstitucionalidade proferida no caso concreto 12

Não se contemplou, inicialmente, a possibilidade de se conferir eficácia erga omnes à decisão do Supremo Tribunal Federal, no controle abstrato de normas ${ }^{13}$. O Tribunal limitava-se, tal como no controle incidental, a informar o Senado Federal sobre a declaração de inconstitucionalidade também no processo de controle abstrato de normas. A este caberia sobre a definitiva suspensão da aplicação da lei declarada inconstitucional ${ }^{14}$

Posteriormente, passou o Tribunal a admitir que as decisões de inconstitucionalidade proferidas no processo de controle abstrato de normas tinham eficácia erga omnes, deixando, assim, de submetê-las ao Senado Federal ${ }^{15}$.
É certo que se essa conclusão se mostrava ensurável para a sentença de inconscionalidade - até porque, do contrário, terเo esvaziamento completo do instituto eria de ser aplicada, igualmente, à eventual laração de constitucionalidade.

Somente em 1977 deixou assente o SupreTribunal Federal que, ao contrário da deo proferida na representação interventiva, a núncia de inconstitucionalidade no procesle controle abstrato de normas era dotada eficácia erga omnes ${ }^{16}$. Essa orientação foi da de forma definitiva em 1975, em resposuma consulta formulada pelo Senado Feal ${ }^{17}$. Segundo a orientação estabelecida pelo remo Tribunal Federal, a eficácia erg nes da pronúncia de inconstitucionalidade ferida no processo de controle abstrato de mas estava vinculada, fundamentalmente, atureza do processo e, independia, portan de qualquer fundamento legal 18

Desde então, não mais se coloca em dúvina doutrina ${ }^{19}$ e na jurisprudência, a eficáerga omnes da pronúncia de inconsicionalidade proferida no processo de conle abstrato de normas 20 . Uma alteração ;terior do Regimento Interno do Supremo bunal Federal deixou assente que, apenas hipótese de decisão proferida no controle idental de normas (art. 178) ${ }^{21}$, estava a irte obrigada a informar o Senado Federal re a declaração de inconstitucionalidade. Admite-se, atualmente, na doutrina que a cácia erga omnes da pronúncia de onstitucionalidade no controle abstrato de rmas tem hierarquia constitucional. Sustense com base no argumento a contrário, treado no art. 52, inciso X, da Constituiग, que a suspensão da aplicação da lei :onstitucional pelo Senado Federal é exigida enas nos casos de declaração incidental de :onstitucionalidade 22

\section{A nulidade ipso jure e ex tunc}

Se o Supremo Tribunal Federal chegar à conclusão, no processo de controle abstrato de normas, de que disposições do direito federal ou do direito estadual revelam-se incompatíveis com a Constituição, então ele as declarará inconstitucionais. A fórmula de censura vem expressa normalmente nos seguintes termos:

"Vistos, relatados ediscutidos estes autos, acor dam os Ministros do Supremo Tribunal Federal, em sessão plenária, na conformidade da ata do julgamento e das notas taquigráficas, por unanimidade de votos, em julgar procedente a Representação, declarando-se a inconstitucionalidade do art da Lei. "23.

$\mathrm{Ou}$, ainda:

"Vistos, relatados ediscutidos estes autos, acor. dam os Ministros do Supremo Tribunal Federal, em sessão plenária, na conformidade da ata do julgamento e das notas taquigráficas, por unanimidade de votos, (...) julgar procedente a Representação" 24

A lei declarada inconstitucional é considerada, independentemente de qualquer outro ato, nula ipso jure e ex tunc ${ }^{25}$.

A disposição declarada inconstitucional no controle abstrato de normas não mais pode ser aplicada, seja no âmbito do comércio jurídico privado, seja na esfera estatal 26 .

Consoante essa orientação, admite-se que todos os atos praticados com base na lei inconstitucional estão igualmente eivados de iliceidade ${ }^{27}$. Essa orientação, que já era dominante antes da adoção do controle abstrato de normas no ordenamento jurídico brasileiro ${ }^{28}$, adquiriu, posteriormente, quase o significado de uma verdade axiomática 29

$\mathrm{Na}$ jurisprudência do Supremo Tribunal Federal pode-se identificar, todavia, tentativa no sentido de, com base na doutrina de Kelsen, abandonar a teoria da nulidade em favor da 
chamada teoria da anulabilidade. Segundo essa concepção, a lei inconstitucional não pode ser considerada nula, porque, tendo sido editada regularmente, gozaria de presunção de constitucionalidade e sua aplicação continuada produziria conseqüências que não podem ser olvidadas ${ }^{30}$. A lei inconstitucional não seria, portanto, nula ipso jure, mas apenas anulável. A declaração de inconstitucionalidade teria, assim, caráter constitutivo ${ }^{31}$. Da mesma forma que o legislador poderia dispor sobre os efeitos da lei inconstitucional ${ }^{32}$, seria facultado ao Tribunal reconhecer que a lei aplicada por longo período haveria de ser considerada como fato eficaz, apto a produzir conseqüências pelo menos nas relações jurídicas entre pessoas privadas e o Poder Público. Esse seria também o caso se, com a cassação de um ato administrativo, se configurasse uma quebra da segurança jurídica e do princípio da boa-fé $\mathrm{f}^{33}$.

É interessante registrar a síntese da argumentação desenvolvida pelo eminente Magistrado:

"Acertado se me afigura, também, o entendimento de que se não deve ter como nulo ab initio ato legislativo que entrou no mundo jurídico munido de presunção de validade, impondo-se, em razão disso, enquanto não declarado inconstitucional, à obediência pelos destinatários os seus comandos. Razoável é a inteligência, a meu ver, de que se cuida, em verdade de ato anulável, possuindo caráter constitutivo a decisão que decreta nulidade. Como, entretanto, em principio, os efeitos dessa decisão operam retroativamente, não se resolve, com isso, de modo pleno, a questão de saber se é mister baver como delitos de orbe jurídico atos ou fatos verificados em conformidade com a norma que haja sido pronunciada como inconsistente com a ordem constitucional. Tenho que procede a tese, consagrada pela corrente discrepante, a que se refere o Corpus Juris Secundum de que a lei inconstitucional é um fato eficaz, ao menos antes da determinação de incons. titucionalidade, podendo ter conseqüências que não é lícito ignorar. A tutela da boa-fé exige que, em determinadas circunstâncias, notadamente quando, sob a lei ainda não declarada incons. titucional, se estabeleceram relações entre o particular epoder público, se apure, prudencialmente, até que ponto a retroatividade da decisão, que decreta a inconstitucionalidade, pode atingir, prejudicando-o, o agente que teve por legítimo o ato e, fundado nele, operou na presunção de que estava procedendo sob o amparo do direito objetivo 334

Essa orientação não provocou qualquer mudança no entendimento anterior relativo à ipso jure ${ }^{35}$, até porque, consoante orientação do Supremo Tribunal Federal, o princípio da supremacia da Constituição não se compadece com uma orientação que pressupõe a validade da lei inconstitucional ${ }^{36}$. O reconhecimento da validade de uma lei inconstitucional - ainda que por tempo limitado - representaria uma ruptura com o princípio da supremacia da Constituição ${ }^{37}$. A lei inconstitucional não pode criar direitos, nem impor obrigações, de modo que tanto os órgãos estatais como o indivíduo estariam legitimamente autorizados a negar obediência às prescrições incompatíveis com a Constituição 38 .

Embora o Supremo Tribunal Federal não tenha logrado formular esta conclusão com a necessária nitidez, é certo que, também ele, parece partir da premissa de que o princípio $\mathrm{da}$ nulidade da lei inconstitucional tem hierarquia constitucional 39 .

$\mathrm{Na}$ Assembléia Constituinte de 1986-88, foi proposta a introdução de dispositivo que autorizava o Supremo Tribunal Federal a determinar se a lei que teve sua inconstitucionalidade declarada no controle abstrato de normas haveria de perder eficácia ex tunc, ou se a decisão deixaria de ter eficácia a partir da data de sua publicação 40 . Esse projeto, que observava, em linhas gerais, o modelo estabelecido no art. 282, $\int 4^{\circ}$, da Constituição Portuguesa ${ }^{41}$, foi rejeitado 42 .

Preservou-se, assim, orientação que considera nula ipso jure e ex tunc a lei inconstitucional.
Esse entendimento tem base constitucioO princípio do Estado de Direito, fixado art. $1^{\circ}$, a aplicação imediata dos direitos tamentais, consagrada no $\llbracket 1^{\circ}$, do art. $5^{\circ}$ aculação dos órgãos estatais aos princípios stitucionais, que daí resulta, a imutabilidade princípios constitucionais, no que concerne direitos fundamentais e ao processo espede reforma constitucional, ressaltam a sunacia da Constituição. Do art. $5^{\circ}$, inciso XI, da Constituição, que assegura a qual$r$ indivíduo que seja impedido de exercer direito constitucionalmente garantido, em srência da omissão dos órgãos legislativos, reito de reivindicar uma atividade legislativa diante a propositura do mandado de nção, pode-se concluir que não apenas os itos fundamentais, mas todos os demais itos subjetivos constitucionalmente asseguวs vinculam os órgãos estatais ${ }^{43}$.

A possibilidade de exercer pretensão a uma idade legislativa mediante processo judiciessalta o princípio da supremacia da Consição e enfatiza a sua pretensão de eficácia.

$O$ poder de que dispõe qualquer juiz ou unal para deixar de aplicar a lei inconscional a um determinado processo (Consição, arts. 97 e 102, inciso III, "a", "b" pressupõe a invalidade da lei e, com isso, a nulidade. A faculdade de negar a aplicação $\mathrm{i}$ inconstitucional corresponde ao direito indivíduo de recusar-se a cumprir a le onstitucional, assegurando-lhe, em última ância, a possibilidade de interpor o recurxtraordinário ao Supremo Tribunal Fedecontra decisão judicial que se apresente, de ima forma, em contradição com a Constião (art. 102, III, "a") 44 .

Tanto o poder do juiz de negar aplicação à inconstitucional, quanto a faculdade asseada ao indivíduo de negar observância à le onstitucional demonstram que o constitue pressupôs a nulidade da lei inconscional.

Nessa medida, é imperativo concordar com ientação do Supremo Tribunal Federal que parece reconhecer hierarquia constitucional ao postulado da nulidade da lei incompatível com a Constituição 45

4. A nulidade da lei e os atos singulares praticados com base no ato normativo declarado inconstitucional

A ordem jurídica brasileira não dispõe de preceitos semelhantes aos constantes do $\$ 79$ da Lei do Bundesverfassungsgericht, que prescreve a intangibilidade dos atos não mais suscetíveis de impugnação ${ }^{46}$. Não deve supor, todavia, que a declaração de inconstitucionalidade afeta todos os atos praticados com fundamento na lei inconstitucional.

Embora a ordem jurídica brasileira não contenha regra expressa sobre o assunto e se aceite, genericamente, a idéia de que $o$ ato fundado em lei inconstitucional está eivado, igualmente, de iliceidade ${ }^{47}$, concede-se proteção ao ato singular, procedendo-se à diferenciação entre o efeito da decisão no plano normativo (Normebene) e no plano do ato singular (Einzelaktebene) através das chamadas fórmulas de preclusão ${ }^{48}$.

Os atos praticados com base na lei inconstitucional que não mais se afigurem suscetíveis de revisão não são afetados pela declaração de inconstitucionalidade 49 .

Vislumbra-se uma exceção a esse entendimento na sentença condenatória penal, uma vez que aqui inexiste prazo para a propositura da revisão.

Nos termos do art. 621 do Código de Processo Penal, a revisão pode ser proposta a qualquer tempo se a sentença condenatória for contrária a texto expresso da lei penal. Esse fundamento abrange, inequivocamente, a sentença penal condenatória proferida com base na lei inconstitucional 50

Admite-se que uma das causas que pode dar ensejo à instauração da ação rescisória no âmbito do processo civil - violação a literal disposição de lei (art. 485, inciso V, do Código Processual Civil) - contempla, também, a 
inconstitucionalidade de uma lei na qual se fundou o juiz para proferir a decisão transitada em julgado 51 . Todavia, a rescisão de sentença proferida com base em uma lei considerada inconstitucional somente pode ser instaurada dentro do prazo de dois anos a contar do trânsito em julgado da decisão (CPC, artigos 485 e 495).

Assim, enquanto no modelo consagrado pelo \$79, (2), da lei do Bundesverfassungsgericht, admite-se a possibilidade de que a execução de sentença calcada em lei inconstitucional seja impugnada mediante embargos à execução (Código de Processo Civil Alemão, \$767), a impugnação de sentença trânsita em julgado, no sistema brasileiro, somente há de se verificar por via de ação rescisória.

Em julgado de 13 de setembro de 1968, explicitou-se essa orientação:

" $A$ suspensão da vigência da lei por inconstitucionalidade torna sem efeito todos os atos praticados sob o império da lei inconstitucional. Contudo, a nulidade da decisão judicial transitada em julgado só pode ser declarada por via de ação rescisória, sendo impróprio o mandado de segurança (...). ${ }^{552}$.

Esse entendimento foi reiterado posteriormente, enfatizándo-se que a execução judicial de uma decisão transitada em julgado não pode ser obstada com a oposição de embargos, uma vez que a nulidade dessa decisão deve ser aferida do âmbito da ação rescisória 53 .

Em acórdão mais recente, ressaltou-se que "a execução (...) está a mparada no respeito à coisa julgada, que se impõe ao Juizo executante, e que impede que, sobre ela (e até que venha a ser regularmente desconstituída a sentença que lhe deu margem), tenha eficácia o acórdão posterior desta Corte

\section{Conclusão}

Em face de todas essas considerações, a tentativa desenvolvida pelo Supremo Tribunal Federal no sentido de preservar as vantagens pecuniárias já pagas a servidores públicos com base numa lei posteriormente declarada inconstitucional parece carecer de qualque fundamentação jurídica mais consistente

Certamente, o princípio da irredutibilidade de vencimentos não se presta para conferir sustentação à tese adotada, uma vez que, tal como assinalado, o princípio da nulidade da le inconstitucional tem, também, hierarquia constitucional.

Não é preciso dizer, outrossim, que os vencimentos irredutíveis são apenas aqueles licitamente percebidos.

Argumentos embasados na idéia de segurança jurídica não se mostram, igualmente, aptos para solver o problema, uma vez que nesse caso, o Tribunal acabaria por substituirse ao legislador.

Cabe ao legislador e não ao Tribunal a definição das chamadas fórmulas de preclusão, que permitem limitar a possibilidade de impugnação ou de revisão de determinado ato concreto, em nome exatamente da idéia de segurança jurídica.

Se $o$ ato praticado com base na lei inconstitucional ainda é suscetível de impugnação, não há como sustentar, juridicamente, a ilegitimidade de sua revisão ou cassação.

Nem se pretenda afirmar que, na espécie, as vantagens eventualmente ingressas no patrimônio do servidor já teriam sido até mesmo despendidas 55

Se tal tese pudesse ser aceita, com muito maior razão dever-se-ia adotar entendimento que repele o pedido de repetição de indébito decorrente da cobrança de tributo instituído por lei posteriormente declarada inconstitucional.

Nesse caso, todavia, tem entendido o $\mathrm{Su}-$ premo Tribunal Federal que, "declarada a inconstitucionalidade (...), não se pode admitir a eficácia da cobrança feita, impondo-se a repetição do cobrado indevidamente" ${ }^{\text {"56. }}$. Ressalte-se que no precedente referido recusou o Supremo Tribunal entendimento do Tribunal de Justiça do Estado do Rio de Janeiro, segundo o qual, "se houve (...) uma prestação de serviços, com que eles se tornem gratuitos, retroati ente, implicaria enriquecimento sem causa ta, afinal, de outros municipes" 57 .

1 essa objeção respondeu o Supremo com guintes argumentos:

$\mathrm{Se}$ (...) a simples atuação estatal não autoriza invalida a cobrança ou o pagamento do trifazendo necessária a imposição de taxa atra'e lei, não se pode reconbecer ao poder públi direito de retenção das importâncias vidamente cobradas sob o fundamento de eventual prestação de serviça. Em verdade, nhecer tal direito de retenção ao ente :tante é fazer tabula rasa do princípio da re "legal $58 "$.

troumento semelhante mostra-se de todo ável à situação jurídica relacionada com imento de vantagens baseadas em lei nstitucional. $O$ fato de as quantias já tesido incorporadas ao patrimônio do serr ou mesmo de já terem sido despendidas confere legitimidade ao pagamento efetuuma vez que as quantias pagas somente , legítimas se efetuadas com base em lei amente válida.

\section{Notas}

$\mathrm{n}^{\circ}$ 122.202, Relator: Ministro Francisco Rezek, DJ

$\mathrm{n}^{\circ}$ 105.789, Relator: Ministro Carlos Madeira, RTJ 8, p. 301.

, $\mathrm{n}^{\circ}$ 122.202, Relator: Ministro Francisco Rezek, DJ .94.

bosa, Rui, Os Atos Inconstitucionais do Congresso Executivo, in: Trabalhos Jurídicos, p. 70-71; idem, reito do Amazonas ao Acre Septentrional, vol. I, p. Campos, F., Direito Constitucional, 1956, vol. I, p. 31; Buzaid, A., Da Ação Direta, P. 130-132; Nunes, ia e Prática do Poder Judiciário, p. 589.

Willoughby, W. W. The constitutional law of the d States vol I 9-10. Cf também Cooley, Thomas reatise on the Constitutional Limitations, 1878, p.

. Buzaid, Alfredo, Da Ação Direta, p. 128-132. Bittencourt, Controle Jurisdicional titucionalidade, p. 141

Bittencourt, Carlos Alberto Lúcio, Controle dicional da Constitucionalidade, p. 140-141.
9 Cf., a propósito, Bittencourt, Controle Jurisdicional da Constitucionalidade, p. 141.

10 Bittencourt, Controle Jurisdicional de Constitucionalidade, p. 144; Nunes, Teoria e Prática do Poder Judiciário, p. 592

11 Cf., a propósito, Prado Kelly, Discurso na Assembléia Constituinte, in: Alencar, Ana Valderez Ayres Neves de, A Competência do Senado Federal para suspender a execução dos atos declarados inconstitucionais, Revista de Informação Legislativa $\mathrm{n}^{\circ}$ 57, 1978 (Janeiro-Março), $\mathrm{p}$ 260; v., também, MS n' 16.512 , Relator: Osvaldo Trigueiro, RTJ no 38 , p. 23, 28, 81 .

12 Ferreira Filho, Manoel Gonçalves, Curso de Direito Constitucional, p. 35; Silva, J. A. da, Curso de Direito Constitucional Positivo, p. 52.

13 A Proposta de emenda à Constituição no ${ }^{\circ}$ 16, de 1965 , continha cláusula que outorgava eficácia erga omnes às decisões declaratórias de inconstitucionalidade proferidas pelo Supremo Tribunal Federal - As disposicões de lei ou pelo Supremo Tribunal Federal - As disposições de lei ou de normativa consideradas inconstitucionais decisão definitiva, perderão eficácia, a partir da decla ração do Presidente do Supremo Tribunal Federal publicada no orgão oficial da União (Proposta de emen da, art. $5^{\circ}$ ). Essa disposição não foi, todavia, aprovada pelo Congresso Nacional, subsistindo, pois, a necessidade de que se encaminhassem as declarações de incons titucionalidade ao Senado Federal para que se efetivasse a suspensão de execução do dispositivo declarado inconstitucional.

14 Rp. no 933 (liminar), Rel.: Ministro Thompson Flores, RTJ n ${ }^{\circ} 76$, p. 342 (343)

15 Parecer do Ministro Rodrigues Alckmin, Sessão Administrativa de 19.06.1974, DJ de 16.05 .1977 , p. 3124 Parecer do Ministro Moreira Alves, de 11.11.1975, DJ 16.05.1977, p. 3123; Ver, também, Bandeira de Mello, O. A. Teoria das Constituições Rígidas, 1980, p. 213. Em 18 A. Teoria das Constituiçoes Rugidas, 1980, p. 213. Em 18 de abril de 1977, o Presidente do Supremo Tribunal Fe deral, Ministro Thompson Flores, determinou que as comunicaçōes ao Senado Federal, para os fins do art. 42, VII, da Constituição de 1967/69, se restringissem às de claraçoes de inconstitucionalidade proferidas incidenter tantum (Cf. Alencar, A Competência do Senado Federa para suspender a execução dos atos inconstitucionais, Revista de Informação Legislativa n ${ }^{\circ}$ 57, 1978, p. 260 (305) 16 Parecer do Ministro Rodrigues Alckmin, de 19 de junho de 1974, in: DJ de 16.05.1977, p. 3124

17 Parecer do Ministro Moreira Alves, de 11 de novem bro de 1975, in: DJ de 16.05.1977, p. 3123; v. também Bandeira de Mello, O. A., Teoria das Constituições Rígidas, p. 213.

18 Parecer do Ministro Moreira Alves, de 11 de novem bro de 1975, in: DJ de 16.05.1977, p. 3123.

19 Em favor da tese da anulabilidade da lei inconstitucional Cf Nery Ferrari Efeitos da Declaraça acedo Inconstitucionalidade, $3^{2}$ edição, São Paulo, 1992, p. 98. 

20 Cf., a propósito, Silva, J. A. da, Curso de Direito Cons-
titucional Positivo, p. 52-53.

21 Regimento Interno do STF na versão de 15.10 .80

22 Silva, J. A. da, Curso de Direito Constitucional Positivo, p. 52; Ferreira Filho, Manoel Gonçalves, Curso de Direito Constitucional, p. 33-35.

23 Cf., também, Rp. no 1305, Relator: Ministro Sydney Sanches, RDA n ${ }^{\circ} 170$, p. 46.

24 Cf. Rp. no 971, Relator: Ministro Djaci Falcão, RTJ $\mathrm{n}^{\circ} 87$, p. 758.

25 Rp. $\mathbf{n}^{\circ}$ 971, Relator: Ministro Djaci Falcão, RTJ $\mathbf{n}^{\circ}$ 87, p. 758; RE no 93.356, Relator: Leitão de Abreu, RTJ $\mathrm{n}^{\circ}$ 97, p. 1369; Rp. no 1016, Relator: Ministro Moreira Alves, RTJ no 95, p. 993; Rp. no 1077, Relator Ministro Moreira Alves, RTJ no 101, p. 503

26 Mello. O. A., Bandeira de, Teoria das Constituições Rígidas, p. 214.

27 Recurso de MS $n^{\circ}$ 17.076, Relator: Ministro Amaral Santos, RTJ n ${ }^{\circ} 55$, p. 744.

28 Buzaid Alfredo, Ač̃o Direta, 130-131; Barbosa Rui Os Atos Inconstitucionais do Congresso do Execu p. 70-71; Polletti, R., Controle de Constitucionalidade das Leis, p. 109 s.

29 Cf., também, Recurso de MS no 17.076, Relator: Ministro Amaral Santos, RTJ nº 55, p. 744; RE n ${ }^{\circ} 103.619$ Relator: Ministro Oscar Corrêa, RDA n ${ }^{\circ} 160$, p. 80. $30 \mathrm{RE} \mathrm{n}^{\circ}$ 79.343, Relator: Ministro Leitão de Abreu, RTJ $n^{\circ} 82$, p. 791 (795).

31 Assim também Miranda, Pontes de, Comentários a Constituição Federal de 1967/69, vol. III, p. 619.

$32 \mathrm{RE} \mathrm{n}^{\circ} 79.343$, Relator: Ministro Leitão de Abreu, RT $n^{\circ} 82$, p. 791 (795).

$33 \operatorname{RE~n}^{\circ}$ 79.343, Relator: Ministro Leitão de Abreu, RT] $n^{\circ} 82$, p. 791 (795).

34 Cf. RE no 79.343, Relator: Ministro Leitão de Abreu RTJ n ${ }^{\circ} 82$, p. 791 (795).

35 Cf. RE $\mathbf{n}^{\circ} 93.356$, Relator: Ministro Leitão de Abreu, RTJ n $n^{\circ}$.

36 Rp. $n^{\circ}$ 971, Relator: Ministro Djaci Falcão, RTJ no

36 Rp. $n^{\circ}$ 971, Relator: Ministro Djaci Falcão, RTJ $n^{\circ}$
87, p. 758; Rp. no 1016, Relator: Ministro Moreira Alves, RTJ no 95 , p. 993; Rp. n ${ }^{\circ}$ 1077, Relator: Ministro Moreira

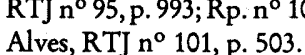

Alves, RTJ $\mathbf{n}^{\circ}$ 101, p. 503 .
37 Rp. $\mathbf{n}^{\circ}$ 980, Relator: Ministro Moreira Alves, RTJ n $^{\circ}$ 37 Rp. $\mathrm{n}^{\circ}$ 980, Relator: Ministro Moreira Alves, RTJ $\mathrm{n}^{\circ}$ 96, p. 496 (508).

38 Rp. $n^{\circ}$ 980, Relator: Ministro Moreira Alves, RTJ $n^{\circ}$ 96, p. 496 (508).

39 Cf. $\operatorname{RE~n}^{\circ}$ 103.619, Relator: Ministro Oscar Corrêa $\mathrm{RDA} \mathrm{n}^{\circ} 160$, p. $80 \mathrm{~s}$.

40 O Projeto do Senador Maurício Corrêa estabelecia verbis: "Art. 127 .....

$2^{\circ}$ Quando o Supremo Tribunal Federal declarar a inconstitucionalidade, em tese, de norma legal ou ato normativo, determinará se eles perderão eficácia desde a sua entrada em vigor, ou a partir da publicação da decisão declaratória" (Cf. a propósito, Silveira, José Néri da, A Dimensão Política do Judiciário, in: Arquivos do Ministério da Justiça n ${ }^{\circ} 173$ (1988), p. 46 (55); Falcão, Djaci, O
Poder Judiciário e a Nova Carta Constitucional, in: Arquivos do Ministério da Justiça ${ }^{\circ} 173$, p. 25 (29).

$41 \mathrm{O}$ art. 282 (4), da Constituição portuguesa:

"Quando a segurança jurídica, razões de equiidade ou interesse público de excepcional relevo, que deverá ser fun damentado, o exigirem, poderá o Tribunal Constitucional fixar os efeitos da inconstitucionalidade ou da ilegal dade com alcance mais restrito do que o previsto nos $n^{\circ}$ 1 e $2^{n}$

42 Cf., a propósito, Silveira, J. Néri da, A Dimensão Política do Judiciário, in: Árquivos do Ministério da Justiça $\mathrm{n}^{\circ} 173$ (1988), p. 46 (55).

43 Cf., a propósito, $\mathrm{MI}^{\circ}{ }^{\circ} 107$, Relator: Ministro Moreira Alves, RTJ no 133 , p. 11

44 Cf., a propósito, Rp. $\mathrm{n}^{\circ}$ 980, Relator: Ministro Moreira Alves, RTJ no 96, p. 496 (508)

$45 \mathrm{Cf}$ a propósito, Rp. $\mathrm{n}^{\circ}$ 980, Relator: Ministro Moreir Alves, RTJ no 96, p. 496 (508); RE no 103.619, Relator Ministro Oscar Corrêa, RDA no 160 , p. 80 s.

$46 \quad 79$ da Lei do Bundesverfassun. "(1) $\$ 9$ da Lei do Bundesverfassungsgericht: (1) E legitimo o pedido de revisão criminal nos termo codigo de Processo Penal contra a sentença condenatoria penal que se baseia em uma norma declara da ou que se assenta em uma interpretação que o Bundesverfassungsgericht considerou incompativel com a Lei Fundamental.

(2) No mais, ressalvado o disposto no $\ 92$ (2), da Lei do Bundesverfassungsgericht ou uma disciplina legal especifica, subsistem integras as decisões proferidas com base em uma lei declarada nula, nos termos do $\$ 78$. É ilegítma a execução de semelhante decisão. Se a execução forçada tiver de ser realizada nos termos das disposições do Código de Processo Civil, aplica-se o disposto no $\$ 767$ das em enriquecimento sem causa".

47 Cf a pruécimento sem causa . Amaral Santos, RTJ no ${ }^{\circ} 55$, p. 744

Amaral Santos, RT nM 55, p. 744. 48 Ipsen, Jörn, Rechtsfolgen der Verfassungswidrigkeit von Normen und Einzelakt, Baden-Baden, 1980, p. 174s 49 Cf. RE no 86.056, Relator: Ministro Rodrigue Alckmin, Diário da Justiça de 01.07.1977.

HC $\mathrm{n}^{\circ}$ 45.232, Relator: Ministro Themístocle Cavalcanti, RTJ no 44, p. $322 \mathrm{~s}$.

$51 \mathrm{MS} \mathrm{n}^{\circ}$ 17.976, Relator: Ministro Amaral Santos, RT $\mathrm{n}^{\circ} 55$, p. 744 s.; $\operatorname{RE~}^{\circ}{ }^{\circ} 86.056$, Relator: Ministro Rodrigues Alckmin, DJ de 01.07.1977.

$52 \mathrm{RMS} \mathrm{n}^{\circ}$ 17.076, Relator: Ministro Amaral Santos, RT $n^{\circ} 55$, p. 744

$53 \mathrm{RE} \mathrm{n}^{\circ}$ 86.056, Relator: Ministro Rodrigues Alckmin Diário da Justiça de 01.07.1977.

54 Reclamação $n^{\circ} 148$, Relator: Ministro Moreira Alves, RTJ n ${ }^{\circ} 109$, p. 463

55 Cf., a propósito, RE 122.202, Relator: Ministro Francisco Rezek, DJ 08.04.94.

56 RE no 103.619 , Relator: Ministro Oscar Corrêa, in: $\operatorname{RDA~n}^{\circ} 160$, p. $80 \mathrm{~s}$. if. $\mathrm{RDA} \mathrm{n}^{\circ} 160$, p. 81

X. $\operatorname{RDA~n}^{\circ} 160$, p. 84.

\section{liografia}

acar, Ana Valderez Ayres Neves de. A competência jenado Federal para suspender a execução dos atos institucionais, Revista de Informação Legislativa n 57 3 (janeiro-março), p. $223 \mathrm{~s}$

osa, Rui, Os Atos Inconstitucionais do Congresso e do utivo (reimpressão), Rio de Janeiro: 1962.

ODireito do Amazonas ao Acre Septentrional y. I Rio aneiro: 1910.

encourt C A Lúcio O Controle Jurisdicional da ritucionalidadedas Leis Rio de Janeiro Forense, 1968 id Alfredo. Da Asano Direta da Declase 1968. :aid, Alfredo. Da As Ro Direta da Declarasao de institucionalida

npos, Francisco Luiz da Silva. Direito Constitucional Rio de Janeiro: 1956.

Jley, Thomas M. Treatise on the Constitutional itations, $4^{2}$. ed., Boston: 1878.

\section{iisões do Supremo Tribunal Federal}

$\mathrm{n}^{\circ}$ 107, Relator: Ministro Moreira Alves, RTJ no 133

$\mathrm{n}^{\circ}$ 933, Relator: Ministro Thompsson Flores, D 55.77, p. 3124.

$n^{\circ}$ 971, Relator: Ministro Djaci Falcão, RTJ no ${ }^{\circ} 87$,

no 980, Relator: Ministro Moreira Alves, RTJ n 96 96.

1016, Relator: Ministro Moreira Alves, RTJ n ${ }^{\circ} 95$

n $^{\circ}$ 1077, Relator: Ministro Moreira Alves, RTJ no p. 503.
$\mathrm{Rp}^{\circ}$ 1305, Relator: Ministro Sidney Sanches, RDA ${ }^{\circ}$ 170, p. 46.

MS n ${ }^{\circ} 16.512$, Relator: Ministro Oswaldo Trigueiro, RT $\mathrm{n}^{\circ} 38, \mathrm{p} .23$.

RMS $\mathrm{n}^{\circ}$ 17.076, Relator: Ministro Amaral Santos, RTJ $\mathrm{n}^{\circ} 55$, p. 744

$\mathrm{RE} \mathrm{n}^{\circ}$ 79.343, Relator: Leitão de Abreu, RTJ no 82, p.

RE no 93.356, Relator: Leitão de Abreu, RTJ no 97, $p$

RE $\mathrm{n}^{\mathrm{o}}$ 103.619, Relator: Ministro Oscar Correa, RDA $\mathrm{n}^{\circ} 160$, p. 80.

RE no 105.789, Relator: Ministro Carlos Madeira, RTJ 118 , p. 301

RE no 122.202, Relator: Ministro Francisco Rezek, DJ, 08.04.94.

Parecer do Ministro Rodrigues Alckmin, de 19 de junho de 1974 (sessão administrativa), in: DJ de 16.05.1977, p. 3124.

Parecer do Ministro Moreira Alves, de 11.11.1975 (sessão administrativa), DJ. 16.05.77, p. 3123.

Ferreira Filho, Manoel Gonçalves. Curso de Direito Cons Ferreira Filho, Manoel Gonçal ves. Curs
titucional, 17. ed., São Paulo: 1988.

Ipsen, Jörn. Rechtsfolgen der Verfasungswidrigkeit von Norm und Einzelakt, Baden-Baden, 1980

Mello, Oswaldo Aranha Bandeira. Teoria das Constitui. çóes Rígidas, 2. ed. São Paulo: 1980.

Nery Ferrari, Regina Maria Macedo. Efeitos da Declaraçãode Inconstitucionalidade, 3. ed. São Paulo: 1992, p. 98. Nunes, José de Castro. Teoria e Prática de Poder Judiciário, Rio de Janeiro: 1943.

Polletti, R. Controle de Constitucionalidade das Leis, Rio de Janeiro: 1985.

Silva, J. A. da. Curso de Direito Constitucional Positivo, 1988.

Silveira, J. Néri da A. A Dimensão Política do Judiciário in: Arquivos do Ministério da Justiça n. 173 p. 7.

Willough W. W. The Constitutional Law of the United States, v. II, New York, 1910 